\title{
Ghostbusters: Using learning analytics and early assessment design to identify and support ghost students
}

\author{
Kelly Linden, Neil Van Der Ploeg, Ben Hicks \\ Charles Sturt University
}

\begin{abstract}
Ghosting is a student behaviour characterised by enrolling in a subject but never participating. Hence, a ghost student who remains enrolled receives a zero-fail grade. From 2022, the Job ready Graduates Package will require that only genuine students have access to Commonwealth assistance at Australian Universities and an institution may need to refund the fees of what are referred to as non-genuine students. In 2019 and 2020, 382 first-year subjects were monitored to identify disengaged students in weeks 3 and 4 of the session using learning analytics and nonsubmission of an early assessment item. Disengaged students were contacted via phone and 2-way SMS and offered timely and targeted support pre census. The total number of domestic undergraduate students receiving a zero fail has decreased during this time. To further reduce the number of ghost students, once identified as disengaged, an engagement should be mandatory to remain in the subject.
\end{abstract}

Keywords: Learning analytics, early assessment item, ghost student, student engagement

\section{Introduction}

Ghost students enrol in at least one subject, remain in the subject post census but never engage in the learning material or attempt any of the assessment items. The names of ghost students appear in subject student lists, yet they are nowhere to be seen. (Salasky, 2020; Stephenson, 2019). Ghosting is a behaviour that disadvantages the student, the institution, and the government. Without an intervention, a ghost student can accrue a substantial student debt and academic failure. Ghost students have a significant impact on institutional quality metrics such as commencing progress rates, course completion and the government receives no return on investment (Stephenson et al., 2021).

The Job-ready Graduates Package of reforms to higher education legislation passed parliament in October 2020 and will come into effect in 2022. These reforms will have wide-ranging effects on Australian tertiary education and include a range of what is framed as student protections. Importantly, the new legislation will ensure that "only genuine students have access to Commonwealth assistance" (DESE, 2021). As it stands, an institution may be required to refund the fees of what is described in the legislation as non-genuine students. Exactly how this will work is unclear and it is expected that TEQSA guidance notes will be released at some point this year to help clarify this, however, some details have been loosely outlined. The legislation states that providers should use various forms of analytics to determine if students are genuine or not, which include: "completing course requirements, completing assessments and monitoring the number of times a student studying online has logged onto the course LMS" (DESE, 2021). Clearly, there is a significant overlap in the definitions of nongenuine students and ghosting. There is no doubt that this legislation is targeted towards reducing the number of ghost students, and the financial cost of funding commonwealth-supported places where seats remain empty. Efforts to understand and reduce ghosting behaviour are needed now more than ever.

The first census date for a commencing student is incredibly important for both the institution and the student. There is a 4-5 week opportunity between students accepting the offer for universities to support students in their transition to Higher Education and assist the student in deciding as to whether university study is the right choice for them. There is much literature on the importance of transition pedagogy and quality early assessment items (Kift, 2015). Assessment is a key driver of student learning in higher education and many students use assessment to define key aspects of the curriculum. Early assessments items, particularly when due before the 
census date, can engage students with the subject in the early weeks of the teaching session. For students who are not engaged in their studies, there is evidence to suggest that non-submission of early assessment can be used to identify and offer targeted support (Cox \& Naylor, 2018; Linden \& Webster, 2019; Nelson et al., 2009). However this has only ever been shown in small pilot studies.

Learning analytics have also provided much promise in identifying disengaged students. Often complex algorithms and models are used to predict at-risk students, with varying degrees of success (Jayaprakash et al., 2014; Lacave et al., 2018; Tempelaar et al., 2018). There is some evidence that approaching the task from a complex systems perspective can lead to promising results, by applying simple rules that take into account a carefully chosen mix of data (Foster \& Siddle, 2020). Both the Higher Education Standards Panel (HESP, 2018) and the Grattan Institute (Norton \& Mackey, 2018) reports include specific recommendations about monitoring student engagement and acting before the census date; this has been on the radar of many institutions for several years. However, the Job-ready Graduates Package increases the accountability of universities, pressuring them to take stronger actions to identify and remove ghost students.

This study involved optimising early assessment item design in approximately 190 key first-year subjects in 2019 and 2020. Non-submission of a pre-census early assessment item and low learning analytic activity were then used to monitor the engagement of almost all commencing, undergraduate students at our regional university. The aim of the study was to identify and provide targeted support to disengaged domestic undergraduate students to reduce the number of students who receive a zero-fail grade. These students were at risk of developing into ghosts and were offered targeted support to help them reach the best outcome possible: either remain in the subject and pass or to unenroll before the census date.

\section{Methods}

In 2019 and 2020 a university-wide retention team worked with academics to incorporate best practice transition pedagogy into key first-year subjects across the three Faculties and the Pathways program at a regional Australian university. Academics were provided with resources based on the current literature and priority access to educational designers to design high quality, engaging low stakes early assessment items that were due at least 3 days prior to the census date in week 4. Ethics approval was received from The Charles Sturt Human Ethics Committee (HREC Protocol No H21170).

A total of 199 subjects in 2019 and 183 subjects in 2020 from across the 3 Faculties were included in the project, which encompassed the majority of commencing undergraduate students and approximately $40 \%$ of all enrolled undergraduate domestic students. In collaboration with the subject coordinator, the project team identified disengaged students in weeks 3 and 4 of each of the three main academic sessions. The timing was critical as it was before the census date, which was on the Friday of week 4. A combination of non-submission of an early assessment item and learning analytics was used to identify disengaged students. A pre-ticked online form was then generated and sent to the subject coordinator, who could remove students they believed to be engaged and add students they were concerned with. To accurately identify students, it was critical that the subject coordinator be involved in the process as many students in difficulty first reach out to the teaching academic. The engagement of 12, 673 students was monitored and across the 3 main academic sessions in 2019 and 20204288 students were identified as disengaged. These students were proactively contacted and offered on-the-spot advice and referral to a variety of support services.

The list of disengaged students was sent to the Student Outreach team, who then used a combination of phone and two-way SMS to contact the students. They were also provided with specific context for the call, including details of the missed assessment item, LMS activity, and contextual information including previous outcomes of past students who had missed that same pre census assessment item. The first contact was usually made within 2 days of the assessment due date, and the conversation was supportive yet realistic. Two types of failing grades are reported. A fail withdrawn (FW) was awarded as a zero-fail to students who did not submit any assessment items. A fail grade (FL) indicates that the student received a failing grade between $1-49 \%$ for the subject.

\section{Findings and Discussion}

Many studies describe complex algorithms and models that predict the likelihood of a student failing their subjects, with varying degrees of accuracy (Jayaprakash et al., 2014; Lacave et al., 2018; Tempelaar et al., 2018). Nuances in student behaviour make it difficult to identify disengaged, or non-genuine students in the first four weeks of the session. Students may enrol late, receive printed lecture notes from a friend, be enrolled in a 
course where all material is delivered face to face, or live in a share house with one computer permanently logged into the LMS. They may receive an extension for an assessment item, decide that $1 \%$ is not worth the effort, or know that blanket extensions are always offered. Our group (Linden et al., 2020) and others (Cox \& Naylor, 2018; Nelson et al., 2009) have previously found that non-submission of a pre-census, early assessment item is an accurate measure of disengagement in small pilots. However, this is the first study to show a successful expansion to cover the enrolment of almost all commencing domestic undergraduate students. Analysis was conducted on a range of available learning analytics, such as clicks, time on site, and the number and date of last site accesses. The date of last access was found to be an accurate measure of disengagement when a student had not accessed the subject LMS during either a 6 or 10 day period from near the end of the third week of the session (Table 1). No activity on the LMS for 6 days is a more sensitive method of detecting future ghost students than 10 days of no activity. However, the false-positive rate is higher- a greater number of students are incorrectly identified who continue on to pass the subject. Of the students enrolled in a subject without a pre census assessment item who received an FW grade, $70 \%$ did not access the LMS in the previous 6 days and only $36 \%$ did not access the LMS in the prior 10 days. It was a surprise that only $72 \%$ of students who received an FW grade in subjects with an early assessment item were identified in the campaign. There are some possible reasons that more $\mathrm{FW}$ grades were not identified, such as students with an extension and those who enrolled late in the subject, however, it is important to note that no process is likely to capture $100 \%$ of students. Furthermore, given support resources are finite, there is a balance that must be found between identifying a greater percentage of students headed for an FW without increasing the false positive rate. Previous research has shown that reducing time since LMS access quickly increases the false positive rate (Van der Ploeg et al, 2020).

Table 1. Comparison of LMS low activity and non-submission of assessment

\begin{tabular}{cccc}
\hline & $\begin{array}{c}\text { Low activity } \\
(6 \text { days })\end{array}$ & $\begin{array}{c}\text { Low activity } \\
(10 \text { days })\end{array}$ & $\begin{array}{c}\text { Non-submission } \\
\text { of assessment }\end{array}$ \\
\hline $\begin{array}{c}\text { Sensitivity } \\
(\% \text { or total FWs identified })\end{array}$ & $70 \%$ & $36 \%$ & $72 \%$ \\
\hline $\begin{array}{c}\text { False positive rate } \\
(\% \text { of identified students who passed }\end{array}$ & $38 \%$ & $33 \%$ & $32 \%$ \\
\hline
\end{tabular}

The average grade distribution of the 382 subjects monitored in 2019 and 2020 is shown in Figure 1. The grade distribution of the students who were not identified as disengaged follows a standard bell curve (Figure 1, blue). The grade distribution of the 4288 students who were identified as disengaged and contacted by the outreach team appears vastly different, with $35 \%$ of students receiving an FW grade and $26 \%$ of genuine students receiving an FL grade (Figure 1, orange). This indicates that the correct students were being offered support, however, there is a substantial number of ghost students who did not heed the advice of the outreach team. This is consistent with the literature (Salasky, 2020; Stephenson, 2019).

Figure 1. Grade distribution for students identified as disengaged and contacted in weeks 3 and 4 (orange) and for all other students enrolled but not contacted

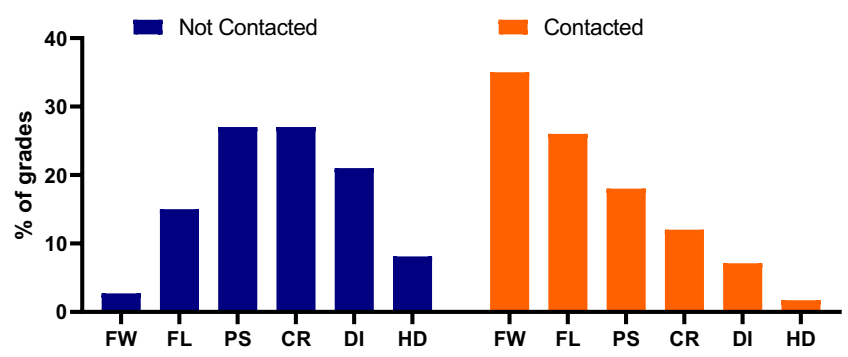

Subjects were selected to ensure that the enrolment of the vast majority of commencing undergraduate students were monitored. When disengaged students were identified and offered targeted support, the outreach team engaged in a holistic conversation regarding a student's course enrolment. This has been reflected in a reduction in the total number of domestic undergraduate students receiving an FW grade since 2018 (Figure 2, orange). The majority of funding for this project was restricted to supporting domestic undergraduate students. At the same time as the number of domestic undergraduate FW grades were decreasing, there has been an upward trend in the number of FW grades awarded to all other students who were not offered targeted support, which includes international undergraduates and all post-graduate students (Figure 2, blue). It is clear that the targeted intervention has reduced the total number of FW grades awarded to domestic undergraduate students at our 
institution. The Job-ready Graduates Package may require that all Australian universities refund the fees of nongenuine students (DESE, 2021). This increases the importance for Australian institutions to identify nongenuine, or ghost undergraduate and postgraduate students before the census date and offer targeted support to engage and succeed or dis-enrol the student. One way to achieve this is by adding an 'opt-in' requirement for students showing strong signs of disengagement (Norton et al, 2018). Including a requirement to complete a task would indicate that not only is the student genuine, but also motivated to engage in their studies.

Figure 2. The number of FW grades awarded in 2018, 2019, and 2020 to domestic undergraduate students (orange) and all other students (blue) including international undergraduates and all postgraduate students

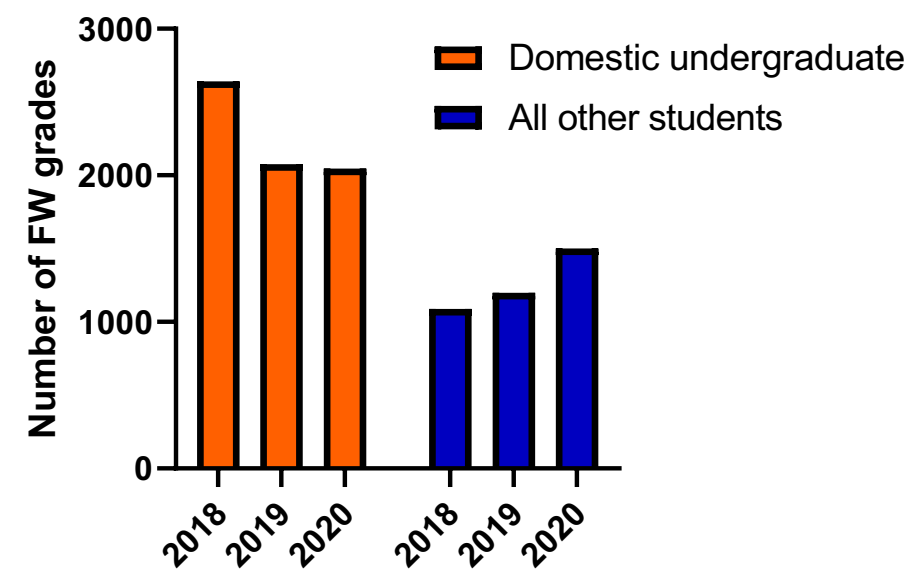

As institutions grapple with the financial implications of withdrawing students, Figure 3 clearly indicates that those students who perform poorly in their commencing session of university have an incredibly low chance of success in their second session of study. Of over 3000 commencing domestic undergraduate students who received a failing grade in session 1 in 2018, 2019, and 2020 (Figure 3, left) 74\% of students withdrew from the university and did not complete a second session of study (right). Only $6 \%$ of students received passing grades and $20 \%$ of students received a combination of FL and FW grades. This makes identifying disengaged continuing students much easier. In the second session of study, if a student has: poor academic history, low LMS activity, non-submission of an assessment item, and does not have a successful dialogue with the outreach team (phone or SMS), there is an extremely small chance of that student passing. The total number of domestic undergraduate students receiving a failing grade is reducing and has decreased by approximately $20 \%$ since 2018.

Figure 3. Receiving a failing grade in the first session of study (left) significantly reduces the chances of success in the second session of study (right)

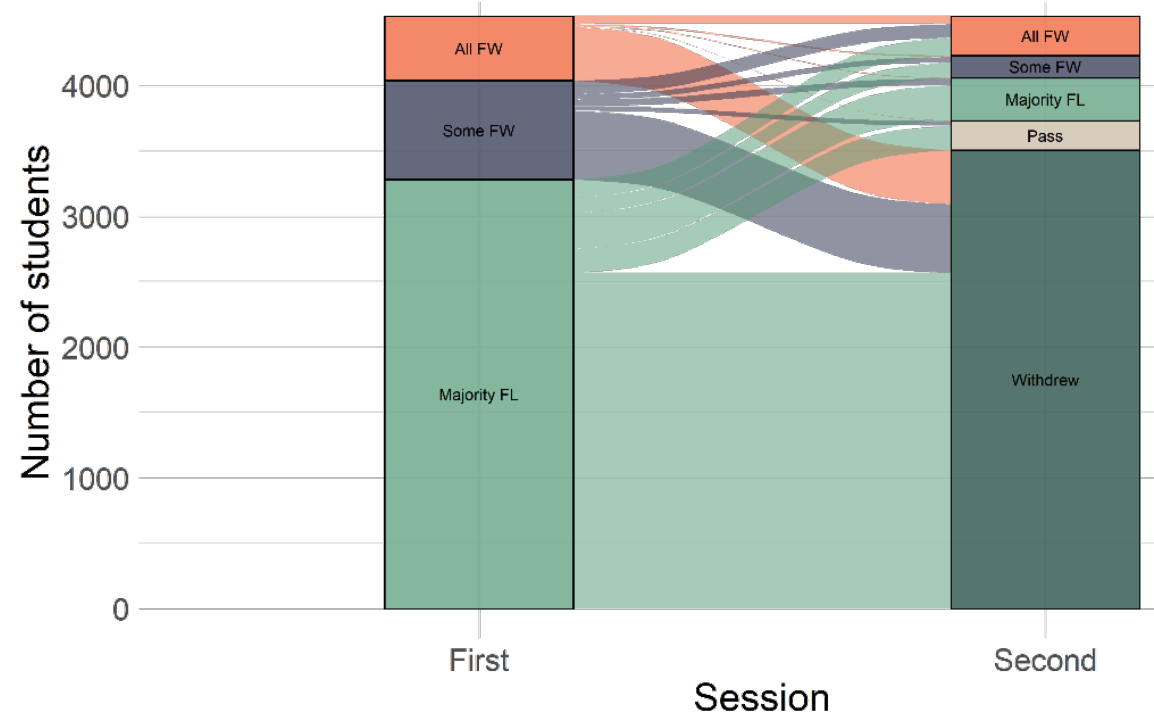




\section{Conclusion}

Both learning analytics and non-submission of assessment are effective methods to identify disengaged or nongenuine students. We have shown that targeted support can reduce the number of failing grades, however, approximately $38 \%$ of students who were initially identified as disengaged in this study were supported to receive a passing grade. It is therefore very difficult to accurately determine genuine vs non-genuine students pre census. For an institution to ensure that only genuine students remain enrolled after the census date and to meet the legislative requirements of the Jobs-ready Graduates Package students must show some level of engagement. This could include submitting the early assessment or completing a small mandatory task. Including a requirement to complete a task would indicate that not only is the student genuine, but also motivated to engage in their studies, reducing the number of ghosts.

\section{References}

DESE. (2021). Job read Graduates Package. Australian Government. https://www.dese.gov.au/job-ready

Cox, S., \& Naylor, R. (2018). Intra-university partnerships improve student success in a first-year success and retention outreach initiative. Student Success, 9(3), 51-65. https://doi.org/10.5204/ssj.v9i3.467

Foster, E., \& Siddle, R. (2020). The effectiveness of learning analytics for identifying at-risk students in higher education. Assessment \& Evaluation in Higher Education, 45(6), 842-854. https://doi.org/10.1080/02602938.2019.1682118

Nelson, K., Duncan, M., \& Clarke, J. (2009). Student success: The identification and support of first year university students at risk of attrition. Studies in Learning Evaluation Innovation and Development, 6(1), 115. https://eprints.qut.edu.au/28064/1/c28064.pdf

Norton, A., Cherastidtham, I., \& Mackey, W. (2018). Dropping out: the benefits and costs of trying university. Grattan Institute.

HESP. (2018). Final Report - Improving retention, completion and success in higher education. Canberra: Australian Government. https://docs.education.gov.au/documents/higher-education-standards-panelfinalreport-improving-retention-completion-and-success

Jayaprakash, S. M., Moody, E. W., Lauría, E. J., Regan, J. R., \& Baron, J. D. (2014). Early alert of academically at-risk students: An open source analytics initiative. Journal of Learning Analytics, 1(1), 6-47. https://doi.org/10.18608/jla.2014.11.3

Kift, S. (2015). A decade of transition pedagogy: A quantum leap in conceptualising the first year experience. HERDSA Review of Higher Education, 2(1), 51-86.

Kift, S. M. (2009). First year curriculum principles: First year teacher. http://transitionpedagogy.com/wpcontent/uploads/2014/05/4FYCPrinciplesFirstYearTeacher_2Nov09.pdf

Lacave, C., Molina, A. I., \& Cruz-Lemus, J. A. (2018). Learning Analytics to identify dropout factors of Computer Science studies through Bayesian networks. Behaviour \& Information Technology, 37(10-11), 993-1007. https://doi.org/10.1080/0144929X.2018.1485053

Linden, K., Van der Ploeg, N., Hicks, B., Wright, M., \& Gonzalez, P. (2020). Peering into the crystal ball of the disengaged: What happens to students that do not submit an early assessment item? 37th International Conference of Innovation, Practice and Research in the Use of Educational Technologies in Tertiary Education: ASCILITE 2020 (pp. 48-53). https://doi.org/10.14742/ascilite2020.0124

Linden, K., \& Webster, L. (2019). Back to Basics: combining analytics and early assessment with personalised contact to improve student progress. 36th International Conference on Innovation, Practice and Research in the Use of Educational Technologies in Tertiary Education (ASCILITE). Singapore. https://2019conference.ascilite.org/assets/papers/Paper-146.pdf

Van der Ploeg, N., Linden, K., Gonzalez, \& Hicks., B. (2020). Widening the net to reduce the debt: Reducing student debt by increasing identification of completely disengaged students. 37th International Conference of Innovation, Practice and Research in the Use of Educational Technologies in Tertiary Education: ASCILITE 2020 (pp. 48-53). https://doi.org/10.14742/ascilite2020.0125

Salasky, J. (2020). Ghost Students. https://doi.org/10.2139/ssrn.3727018

Stephenson, B. (2019). Universities must exorcise their ghost students. Times Higher Education, 30.

Stephenson, B., Cakitaki, B. M., \& Luckman, M. M. (2021, March). "Ghost student” failure among equity cohorts: Towards understanding Non-Participating Enrolments (NPE). National Centre for Student Equity in Higher Education. https://www.ncsehe.edu.au/publications/ghost-student-failure-equity-cohorts-nonparticipating-enrolments/

Tempelaar, D., Rienties, B., Mittelmeier, J., \& Nguyen, Q. (2018). Student profiling in a dispositional learning analytics application using formative assessment. Computers in Human Behavior, 78, 408-420. https://doi.org/10.1016/j.chb.2017.08.010 
Linden, K., Van Der Ploeg, N., \& Hicks, B. (2021). Ghostbusters: Using learning analytics and early assessment design to identify and support ghost students. In Gregory, S., Warburton, S., \& Schier, M. (Eds.), Back to the Future - ASCILITE '21. Proceedings ASCILITE 2021 in Armidale (pp. 54-59).

https://doi.org/10.14742/ascilite2021.0108

Note: All published papers are refereed, having undergone a double-blind peer-review process.

The author(s) assign a Creative Commons by attribution licence enabling others to distribute, remix, tweak, and build upon their work, even commercially, as long as credit is given to the author(s) for the original creation.

(C Linden, K., Van Der Ploeg, N., \& Hicks, B. 2021 